\title{
Deep brain stimulation for intractable neuropathic facial pain
}

\author{
Sharona Ben-Haim, MD, ${ }^{1}$ Zaman Mirzadeh, MD, PhD, ${ }^{2}$ and William S. Rosenberg, MD³ \\ ${ }^{1}$ Department of Neurosurgery, University of California, San Diego, California; ${ }^{2}$ Department of Neurosurgery, Barrow Neurological \\ Institute, Phoenix, Arizona; and ${ }^{3}$ Center for the Relief of Pain, Kansas City, Missouri
}

\begin{abstract}
OBJECTIVE Deep brain stimulation (DBS) is a well-established, evidence-based therapy with FDA approval for Parkinson's disease and essential tremor. Despite the early successful use of DBS to target the sensory thalamus for intractable facial pain, subsequent studies pursuing various chronic pain syndromes reported variable efficacy, keeping DBS for pain as an investigational and "off-label" use. The authors report promising results for a contemporary series of patients with intractable facial pain who were treated with DBS.
\end{abstract}

METHODS Pain outcomes for 7 consecutive patients with unilateral, intractable facial pain undergoing DBS of the ventral posteromedial nucleus of the thalamus (VPM) and the periaqueductal gray (PAG) were retrospectively reviewed. Pain was assessed preoperatively and at multiple postoperative time points using the visual analog scale (VAS), the Short-Form McGill Pain Questionnaire-2 (SF-MPQ-2), and the Pain Disability Index (PDI).

RESULTS VAS scores significantly decreased from a mean \pm SD of $9.0 \pm 1.3$ preoperatively to $2.6 \pm 1.5$ at 1 year postoperatively $(p=0.001)$. PDI scores decreased from a mean total of 48.5 to $28.5(p=0.01)$. SF-MPQ-2 scores decreased from a mean of 4.6 to $2.4(p=0.03)$. Notably, several patients did not experience maximum improvement until 6-9 months postoperatively, correlating with repeated programming adjustments.

CONCLUSIONS DBS of the VPM and PAG is a potential therapeutic option for patients suffering from severe, intractable facial pain refractory to other interventions. Improved efficacy may be observed over time with close follow-up and active DBS programming adjustments.

https://thejns.org/doi/abs/10.3171/2018.5.FOCUS18160

KEYWORDS chronic pain; deep brain stimulation; facial pain; neuromodulation; trigeminal neuropathic pain

$\mathrm{D}$ EEP brain stimulation (DBS) is a well-established evidence-based therapy for patients with Parkinson's disease ${ }^{8,18,23,26,27}$ and essential tremor, ${ }^{2,19}$ and it is approved for dystonia ${ }^{14,25}$ and obsessive-compulsive disorder under a humanitarian device exemption. Although not yet supported by Level I evidence, DBS has demonstrated efficacy in patients with epilepsy, ${ }^{9}$ Tourette's syndrome, ${ }^{24}$ depression, ${ }^{6,17}$ and anorexia. ${ }^{16}$ Despite the early successful use of DBS in the 1970s to target the somatosensory thalamus for intractable facial pain, ${ }^{13}$ heterogeneous studies pursuing various chronic pain syndromes have resulted in a range of reported efficacy, keeping DBS for pain as an investigational and "off-label" use.
In the 1970s and 1980s, DBS was widely used to treat patients with medically refractory pain syndromes and was considered safe and effective. ${ }^{10}$ In 1989, medical devices were brought under the jurisdiction of the US FDA, which required device manufacturers to undertake clinical trials documenting safety and efficacy before the devices were granted official labeling. Subsequently, 2 clinical trials conducted by the device manufacturer failed to meet predefined efficacy criteria, and FDA approval was not sought.

As this decision resulted in a dramatic shift away from further exploration of DBS for intractable pain syndromes, it is important to understand how these trials were con-

ABBREVIATIONS DBS = deep brain stimulation; MVD = microvascular decompression; PAG = periaqueductal gray; PDI = Pain Disability Index; PNFS = peripheral nerve field stimulation; SF-MPQ-2 = Short-Form McGill Pain Questionnaire-2; VAS = visual analog scale; VPM = ventral posteromedial nucleus of the thalamus.

SUBMITTED May 15, 2018. ACCEPTED May 21, 2018.

INCLUDE WHEN CITING DOI: 10.3171/2018.5.FOCUS18160. 
ducted. In fact, the trials were a collection of prospective case series, not randomized or otherwise controlled, that produced data that would be difficult to publish today because of a combination of poor recruitment and high attrition (up to $73 \%$ at some follow-up intervals). An expert review $^{7}$ of these trials lacked significant details and indepth analysis of the trial protocols, including the method of follow-up and outcome assessment tools. Patient selection criteria varied widely, as the treated pain syndromes ranged from mechanical low-back and leg pain to thalamic pain syndrome, spinal cord injury, brachial plexopathy, and pain resulting from "accidents." Moreover, there were no reports of lead placement accuracy data, stimulation parameter optimization schedules, or, notably, the reasons for patient withdrawal from the studies, which resulted in a high attrition rate. Finally, these studies were conducted relatively early in the development of DBS, which has since undergone substantial improvement and standardization of technique with the advent of new hardware design and improved targeting modalities.

Presently, DBS for intractable neuropathic pain continues to be performed outside the US. It is approved by health regulatory agencies in Canada and in some European countries, and it is performed off-label at a handful of centers in the US. There is a growing contemporary experience with this procedure, with several groups continuing to refine their approach to DBS for neuropathic pain, examining its efficacy by indication (e.g., phantom limb pain, ${ }^{20}$ poststroke pain, ${ }^{4}$ and neuropathic cephalalgia ${ }^{11}$ ) and by target (e.g., thalamus or periaqueductal gray [PAG], ${ }^{4,22}$ anterior cingulate cortex, ${ }^{5}$ and anterior limb of the internal capsule $^{15}$ ) and modernizing the technical approach to DBS to follow current standards in movement disorder surgery.

In the current study, we evaluated the efficacy of DBS of the ventral posteromedial nucleus of the thalamus (VPM) and the PAG in 7 patients who had refractory neuropathic facial pain. Standardized outcome measures were used preoperatively and postoperatively to report results in these patients, with special attention paid to the importance of close postimplantation follow-up and ongoing stimulation parameter optimization. This report highlights the fact that clinical response rates to DBS for neuropathic pain continue to improve with continued active optimization over long-term follow-up.

\section{Methods \\ Patient Selection}

Seven consecutive patients with unilateral, intractable neuropathic facial pain were identified as potential candidates for DBS surgery between 2011 and 2016. Patients were considered for DBS after extensive conservative management failed, including adequate trials of pharmacological treatments as well as regional nerve blockade. Six of the 7 patients also did not respond to other invasive surgical treatments, including percutaneous Gasserian ganglion procedures, peripheral nerve field stimulation (PNFS) of the face, radiosurgery, and microvascular decompression (MVD). Informed consent regarding the nature, risks, and benefits of DBS for pain was obtained from all patients prior to surgical intervention. Institution- al review board approval was not required for this study because of its retrospective nature.

\section{Targets}

In all patients, attempted targets included the VPM and the PAG. The VPM was targeted approximately $8 \mathrm{~mm}$ posterior to the midcommissural point, approximately 10 $12 \mathrm{~mm}$ lateral, and roughly at the level of the midcommissural point $(\mathrm{z}=0)$, as previously described. ${ }^{4}$ The PAG was targeted approximately $2-3 \mathrm{~mm}$ ventrolateral to the aqueduct at the level of the superior colliculus (although sensory mapping often resulted in placement slightly caudal to the superior colliculus). All patients were implanted with Medtronic Model 3387 quadripolar electrodes (Medtronic, plc) with $1.5-\mathrm{mm}$ contacts spaced $1.5 \mathrm{~mm}$ apart.

In 5 patients, leads were successfully implanted in both targets in the contralateral hemisphere; in 2 patients, only 1 lead was implanted. In 1 of these 2 patients, an attempt to implant a lead in the PAG nucleus violated the ventricle, and therefore only the VPM lead was implanted. In the second patient, PAG lead implantation successfully elicited paresthesias in the contralateral face; however, intraoperative testing during placement of the VPM lead failed to achieve acceptable somatotopic coverage, and the VPM lead was ultimately not implanted.

\section{Operative Technique}

Before the procedure, each patient underwent placement of skull-based fiducials under local anesthesia and subsequent preoperative CT scanning. The fiducials were then registered using the Medtronic StealthStation surgical navigation system (Medtronic, plc). These images were fused to a preoperative MRI with previously planned targets. All procedures were performed by one surgeon (W.S.R.) at a single institution. A unilateral burr hole was preplanned to accommodate the VPM or PAG target (or both) through a transfrontal extraventricular trajectory on or near the coronal suture. Intraoperative macroelectrode stimulation was performed from approximately $5 \mathrm{~mm}$ above the target to approximately $3 \mathrm{~mm}$ below the target, depending on the trajectory and the patient's anatomy, with an attempt to elicit sensation in the desired somatotopic distribution of the face and to evaluate any unexpected adverse effects of stimulation. We used the distal contact in a bipolar configuration to commence stimulation, usually at $1-4 \mathrm{~V}$. The electrode was moved, as necessary, to achieve appropriate somatotopic coverage, and intervals of between 1.5 and 2 $\mathrm{mm}$ along the trajectory were tested. During implantation of the PAG lead, the patient would often report a warm, pleasant sensation in a rough somatotopic distribution. To find the appropriate region correlating to the contralateral face, we adjusted the lead location based on an assumed inverted rostrocaudal somatotopy of the PAG. ${ }^{21}$ Once an acceptable location was confirmed, each lead was secured and attached to a trial extension, which was tunneled out of the skin through a separate stab incision and externalized (Fig. 1). Patients were admitted for observation, and discharged home for the trial period, which lasted from 9 to 63 days (Table 1). After a successful trial, the patient was brought back to the operating room for internaliza- 

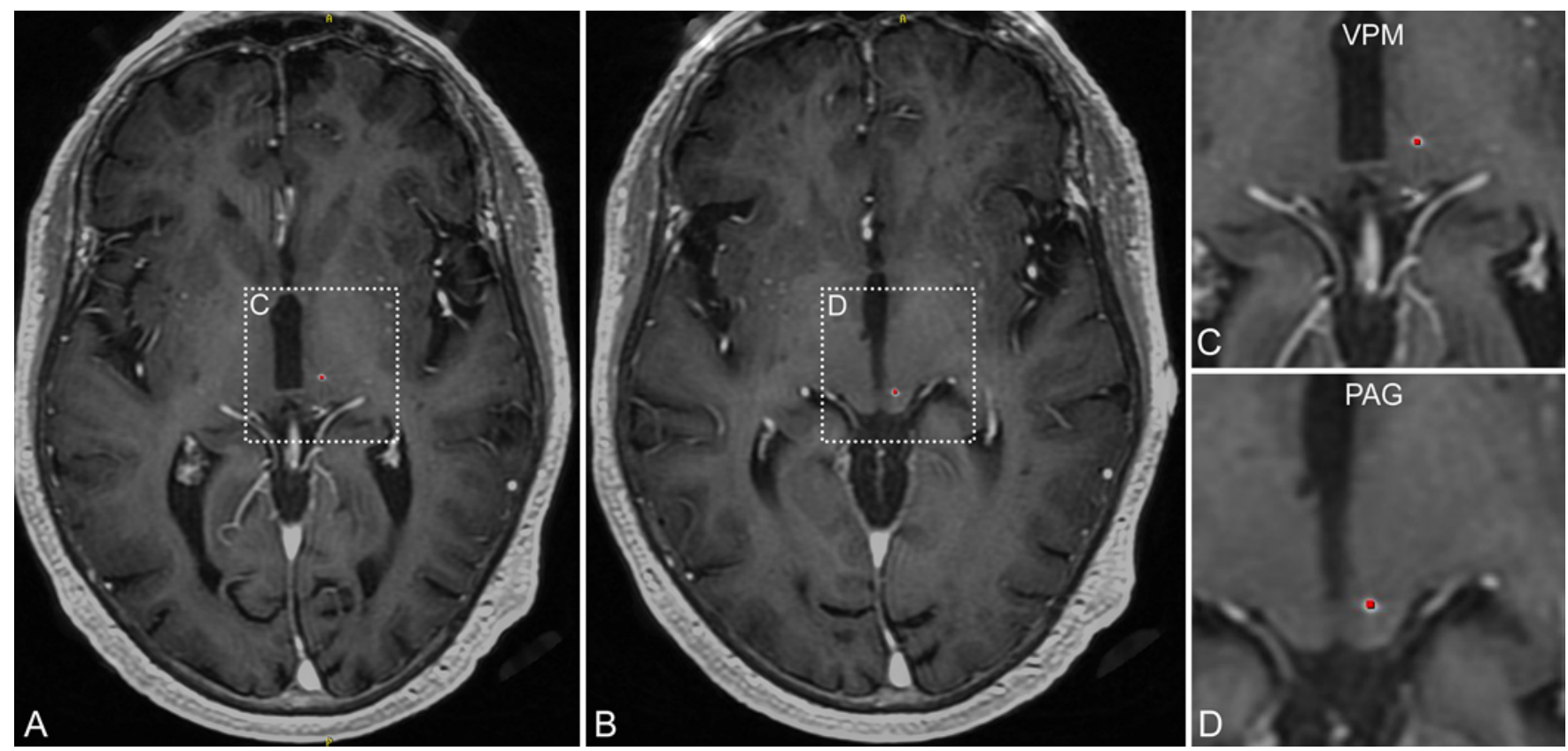

FIG. 1. CT-MRI fusion images showing position of contact 1 for the VPM (A and C [enlarged view]) and PAG (B and D [enlarged view]) leads (red dots).

tion and placement of an infraclavicular implantable pulse generator.

\section{Postoperative Follow-Up}

Postoperatively, patients underwent intensive follow-up with DBS reprogramming as necessary every 2-4 weeks. Four programs (on average) were given to the patients at each follow-up visit, and the patients were required to keep a diary to document their pain scores with the corresponding program in use. Patients were then followed routinely on a monthly basis with decreasing frequency after adequate pain relief had been achieved. Visual analog scale (VAS) scores were recorded at each visit. Patients were administered the Short-Form McGill Pain Question- naire-2 (SF-MPQ-2) and the Pain Disability Index (PDI) preoperatively and again postoperatively at $13-50$ months of follow-up. Programming parameters at the time of the last postoperative visit were noted (Tables 2 and 3). In the 5 patients who had both the VPM and PAG leads implanted, both leads were actively programmed and used simultaneously. Statistical analysis was performed using SPSS software (SPSS, Inc.), with 2-tailed unpaired t-tests used to evaluate the differences between means. A $p$ value $<0.05$ was considered significant.

\section{Results}

All 7 patients reported significant pain reduction and significant improvement in their quality of life during the

TABLE 1. Patient demographics

\begin{tabular}{|c|c|c|c|c|c|c|}
\hline $\begin{array}{l}\text { Pt } \\
\text { No. }\end{array}$ & $\begin{array}{l}\text { Age (yrs) } \\
\text { Sex }\end{array}$ & Diagnosis & $\begin{array}{l}\text { Pain Duration } \\
\text { (yrs) }\end{array}$ & Target & Prior Procedures & $\begin{array}{c}\text { DBS Trial } \\
\text { Length (Days) }\end{array}$ \\
\hline 1 & $49, \mathrm{~F}$ & Atypical It facial pain & 25 & Rt VPM \& PAG & PNFS denied by insurance & 33 \\
\hline 2 & $56, M$ & Poststroke rt facial pain & 1 & Lt VPM \& PAG & None & 9 \\
\hline 3 & $34, \mathrm{M}$ & $\begin{array}{l}\text { Posttraumatic It eye pain secondary } \\
\text { to metallic injury to eye }\end{array}$ & 4 & Rt VPM \& PAG & PNFS inserted \& removed after $1 \mathrm{yr}$ & 63 \\
\hline 4 & $40, F$ & $\begin{array}{l}\text { Facial deafferentation pain from } \\
\text { brainstem glioma }\end{array}$ & 3 & Lt VPM \& PAG & $\begin{array}{l}\text { Brainstem glioma resection, VPS, } \\
\text { balloon compression } \times 2\end{array}$ & 14 \\
\hline 5 & $67, M$ & Poststroke It facial pain & 5 & Rt VPM lead & $\begin{array}{l}\text { Balloon compression, PNFS implant } \\
\quad \text { \& removal after } 1 \mathrm{yr}\end{array}$ & 12 \\
\hline 6 & $69, M$ & Atypical It facial pain & 40 & Rt VPM \& PAG & $\begin{array}{l}\text { Radiofrequency ablation, balloon } \\
\text { compression } \times 2 \text {, failed PNFS trial }\end{array}$ & 50 \\
\hline 7 & $71, \mathrm{~F}$ & $\begin{array}{l}\text { Atypical It facial pain \& postsurgical } \\
\text { facial deafferentation pain }\end{array}$ & 23 & Rt PAG lead & $\begin{array}{l}\text { MVD w/ selective rhizotomy, balloon } \\
\text { compression }\end{array}$ & 35 \\
\hline
\end{tabular}

$\mathrm{Pt}=$ patient; $\mathrm{VPS}=$ ventriculoperitoneal shunt placement. 
TABLE 2. Programming parameters of the VPM

\begin{tabular}{ccccc}
\hline Pt No. & Contacts & Frequency $(\mathrm{Hz})$ & PW $(\mu \mathrm{sec})$ & $\mathrm{Amp}(\mathrm{V})$ \\
\hline 1 & $1+2-$ & 30 & 150 & $1-5$ \\
\hline 2 & $0-\mathrm{C}+$ & 40 & 180 & 2 \\
\hline 3 & $3-\mathrm{C}+$ & 30 & 180 & 4 \\
\hline 4 & $0+1-$ & 30 & 170 & $1-5$ \\
\hline 5 & $0+2-3-$ & 70 & 180 & 3 \\
\hline 6 & $0-\mathrm{C}+$ & 50 & 90 & 3 \\
\hline 7 & $\mathrm{NA}$ & - & - & - \\
\hline
\end{tabular}

Amp = amplitude; NA = not applicable; $\mathrm{PW}=$ pulse width .

trial period and subsequently had the leads implanted. Patient age at the time of surgery ranged from 34 to 71 years, with a mean of 55.1 years (Table 1). All patients experienced unilateral, intractable facial pain of various etiologies, with a duration ranging from 1 to 40 years (mean 14.4 years). Mean preoperative VAS scores were 9 of 10 for all participants. Surgical complications included transient double vision (1 patient), which was determined to be unrelated to stimulation settings and was probably a consequence of lead passage, although the precise etiology is uncertain. Patients were followed $13-50$ months after implantation. Three patients (patients 5, 6, and 7) died of unrelated causes more than 1 year after surgery. Patient 5 , who underwent DBS for poststroke facial pain, died secondary to another stroke 2 years and 7 months after implantation. Patient 6 died 1 year and 2 months after implantation, but we have no record of his cause of death. He was monitored until the 12-month follow-up point with no signs of complications or deterioration. Patient 7 died secondary to cancer 4 years and 2 months after implantation. This patient, who had a history of colon cancer, underwent resection 1 year before implantation and was believed to be in remission at the time of DBS surgery.

Postoperatively, VAS scores were obtained for all $7 \mathrm{pa}-$ tients for at least 1 year. At the 12-month follow-up, VAS scores were significantly decreased from a mean \pm SD of $9.0 \pm 1.3$ preoperatively to $2.6 \pm 1.5$ postoperatively $(\mathrm{p}=$ $0.001)$. The mean percentage improvement among all participants was $70 \%$, with 6 patients achieving greater than $50 \%$ improvement (Table 4). Notably, several patients did not experience maximum improvement until 6-9 months postoperatively, which correlated with repeated programming adjustments (Fig. 2).

TABLE 3. Programming parameters of the PAG/PVG

\begin{tabular}{ccccc}
\hline Pt No. & Contacts & Frequency $(\mathrm{Hz})$ & PW $(\mu \mathrm{sec})$ & $\mathrm{Amp}(\mathrm{V})$ \\
\hline 1 & $1-2+$ & 30 & 150 & $1-5$ \\
\hline 2 & $0-\mathrm{C}+$ & 40 & 180 & 1.6 \\
\hline 3 & $1+2-3+$ & 60 & 160 & 1.7 \\
\hline 4 & $1-0+$ & 30 & 170 & 2.2 \\
\hline 5 & $\mathrm{NA}$ & - & - & - \\
\hline 6 & $4 \mathrm{C}+$ & 50 & 90 & 3 \\
\hline 7 & $0-1+$ & 30 & 200 & $1-3.2$ \\
\hline
\end{tabular}

PVG = periventricular gray.
TABLE 4. Comparison of preoperative and 12-month postoperative VAS scores

\begin{tabular}{lccc}
\hline & \multicolumn{2}{c}{ VAS Score } & \multirow{2}{*}{ VAS } \\
\cline { 2 - 3 } Pt No. & Preop & Postop & Reduction \\
\hline 1 & 8 & 5 & 38 \\
\hline 2 & 8 & 2 & 75 \\
\hline 3 & 10 & 4 & 60 \\
\hline 4 & 7 & 3 & 57 \\
\hline 5 & 10 & 2 & 80 \\
\hline 6 & 10 & 1 & 90 \\
\hline 7 & 10 & 1 & 90 \\
\hline Mean \pm SD $^{*}$ & $9.0 \pm 1.3$ & $2.6 \pm 1.5$ & 70 \\
\hline
\end{tabular}

${ }^{*} p=0.001$ (preoperative vs postoperative).

The PDI was administered preoperatively to all patients and postoperatively to the 4 surviving patients (Fig. 3). Overall, PDI scores decreased from a mean total of 48.5 to 28.5 ( $\mathrm{p}=0.01)$. Decreases were observed across all domains, with the greatest absolute gains made in the categories of "occupation" (mean pre-DBS score of 10, mean post-DBS score of 5.75) and "social activity" (mean preDBS score of 8, mean post-DBS score of 4), and the least absolute gains made in the category of "sexual behavior" (mean pre-DBS score of 7.25 , mean post-DBS score of $6.5)$.

The SF-MPQ-2 was similarly administered postoperatively to the 4 surviving patients (Fig. 4). Scores were calculated on the basis of the mean of each subcategory of pain descriptor (continuous, intermittent, neuropathic, affective). Preoperative scores ranged from 3.7 to 5.4, with a mean score of 4.6 , whereas postoperative scores ranged from 1.3 to 3.8 , with a mean score of $2.4(p=0.03)$. The highest preoperative pain scores were reported in the subcategories of "sharp" (mean preoperative score of 8 , mean postoperative score of 3.25), "tiring" (mean preoperative score of 8, mean postoperative score of 3.4), "shooting" (mean preoperative score of 7.5, mean postoperative score of 2.5), and "throbbing" (mean preoperative score of 7.25, mean postoperative score of 2.9).

\section{Discussion}

Our findings showed successful results for DBS of the VPM and PAG in 7 patients with severe, unilateral neuropathic facial pain of various etiologies who had exhausted medical management and a variable constellation of other invasive procedures. All patients who trialed DBS were ultimately implanted, with a mean externalized trial length of 9-63 days involving frequent follow-up and programming adjustments.

Six of the 7 patients in our cohort achieved greater than a 50\% decrease in VAS score at the 12-month follow-up, with a mean pain reduction of $70 \%(\mathrm{p}=0.001)$. Unfortunately, 3 patients died of causes unrelated to DBS after that time and were not included in subsequent analyses. For the 4 remaining patients, the SF-MPQ-2 and PDI were administered at 13-50 months of follow-up. These results are limited because of the small sample size but reveal 
Ben-Haim et al.

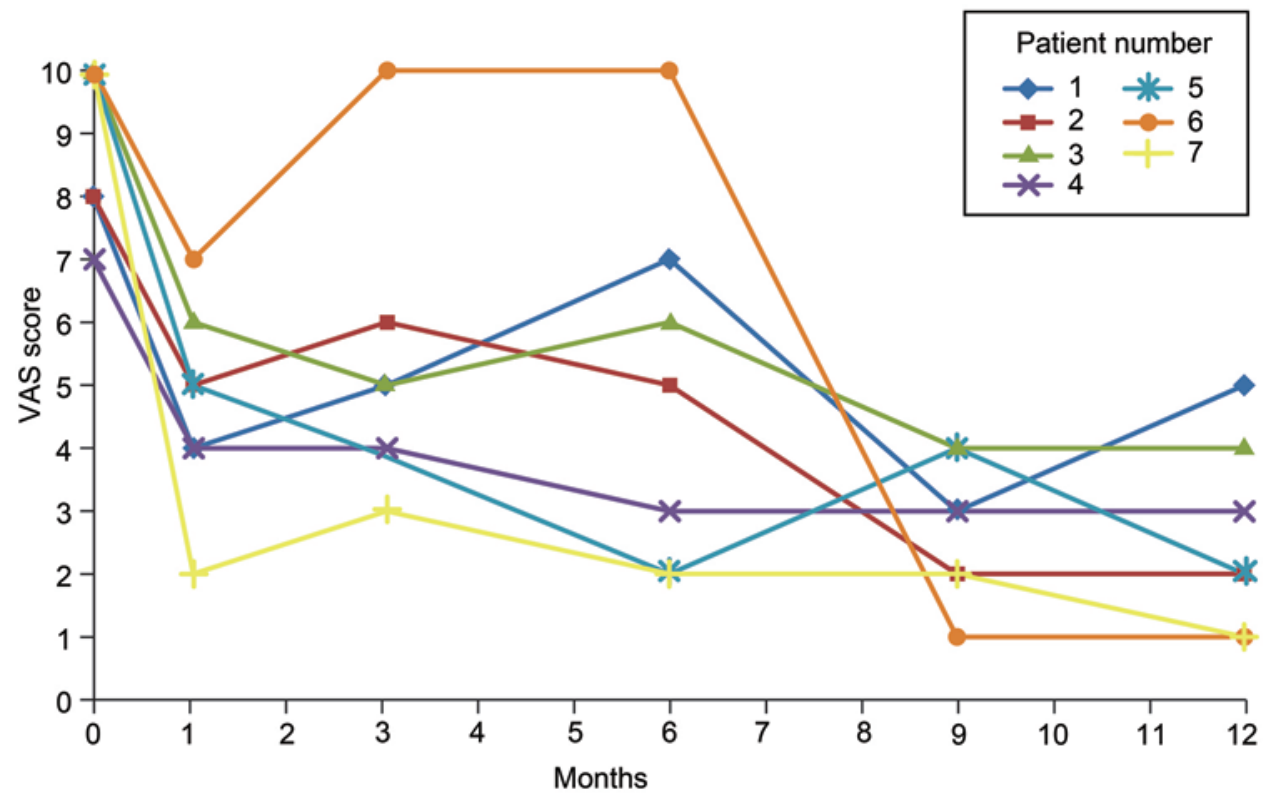

FIG. 2. Graph of VAS scores for the 7 patients.

significant improvements in multiple domains. The PDI subgroup analysis is divided into 7 subcategories (family/ home, recreation, social activity, occupation, sexual behav-

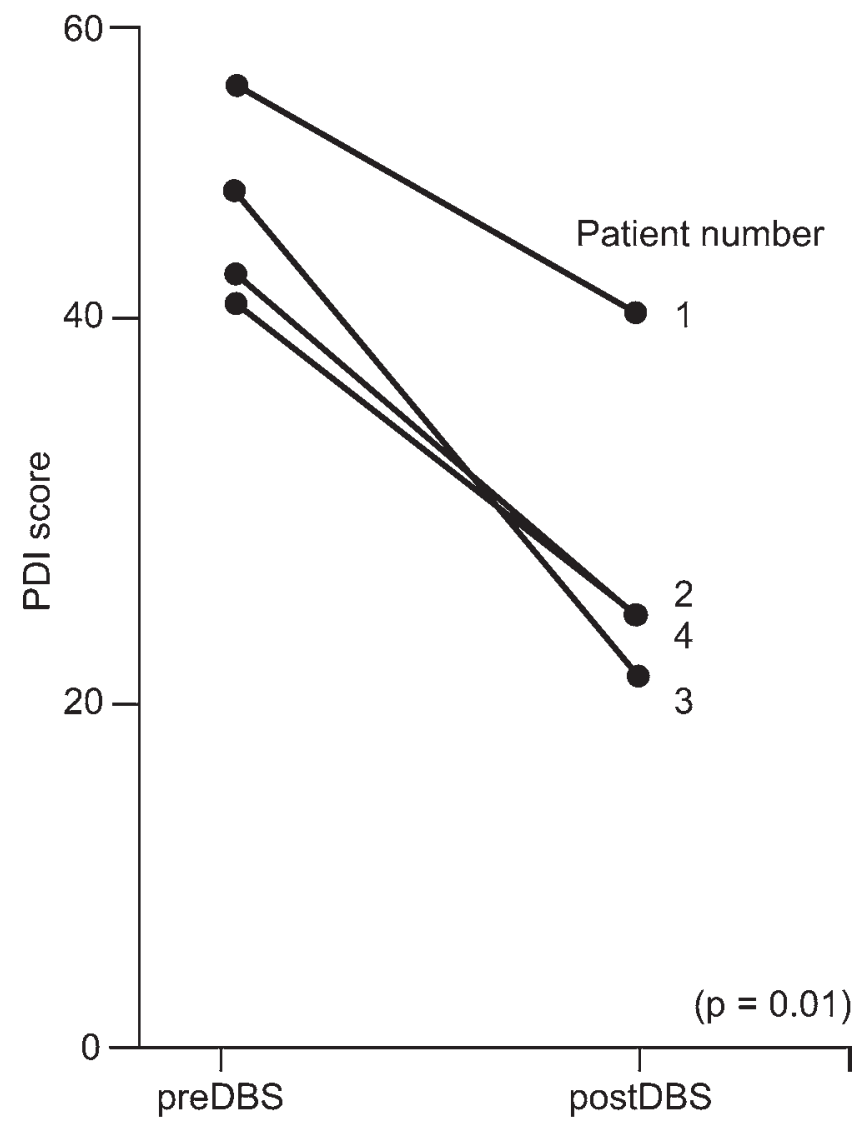

FIG. 3. Graph of PDI scores before and after DBS. ior, self-care, life support), and subgroup analysis revealed global improvement with the greatest absolute gains in the categories of "occupation" and "social activity," as several

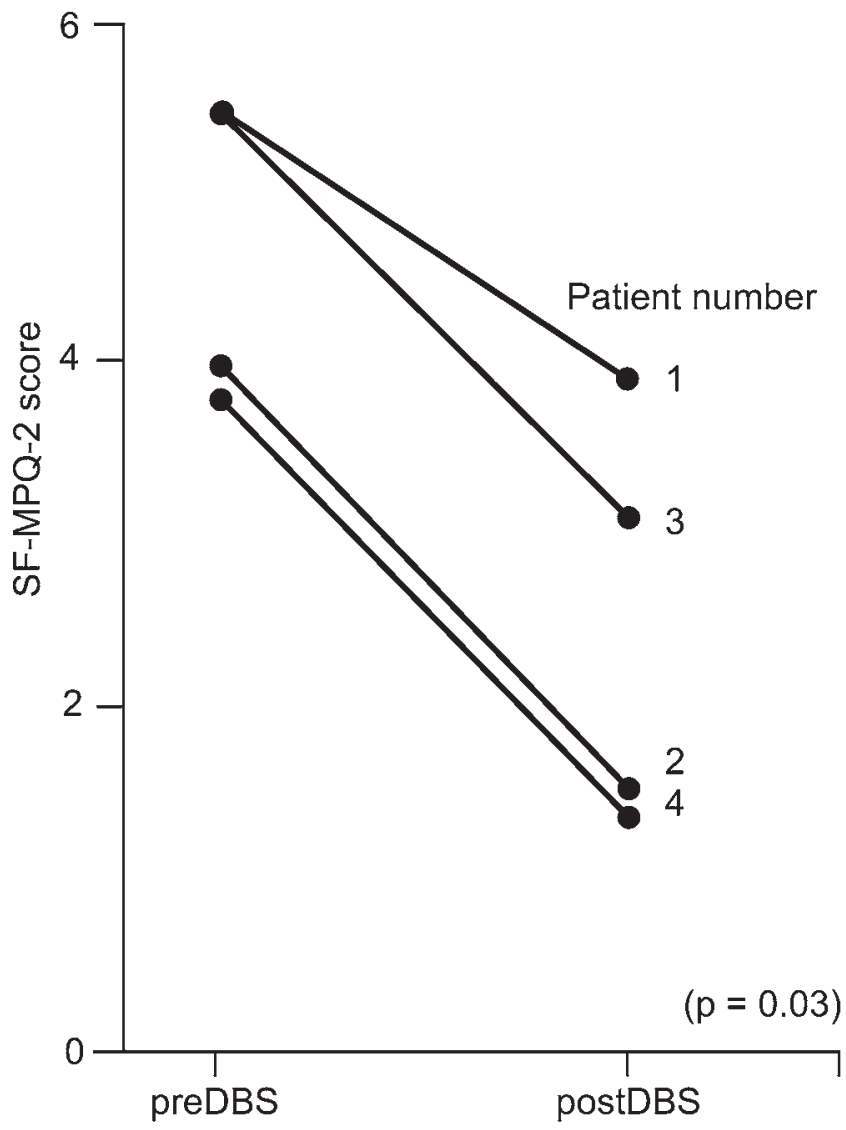

FIG. 4. Graph of SF-MPQ-2 scores before and after DBS. 
patients who were previously unemployed because of pain were able to resume working. Interestingly, the SF-MPQ-2 subgroup analysis did not show significant differences in severity of pain among the 4 qualitative domains (continuous, intermittent, neuropathic, affective). On average, equally significant improvements were made in each domain, with improvement from a mean score of $4.6 \pm 0.45$ to $2.4 \pm 0.61(\mathrm{p}=0.03)$.

Notably, in our VAS analysis, maximal pain relief was not achieved by several patients in our cohort until 6-9 months of follow-up (Fig. 2). During this period, patients were actively followed with clinic visits on a monthly basis, which included programming interrogations and adjustments performed at each visit until adequate pain relief was obtained. Patients were often given up to 4 programs to trial in between follow-up periods and were required to keep a diary of usage. This diary was indispensable as it was consulted to correlate clinical outcome with the specific parameters of each program, allowing gradual refinement of these parameters to maximize pain relief. We noted that during patient trials and after permanent implantation, patients often did not experience the maximum benefit from a particular program for several days to several weeks.

Although the underlying mechanisms of DBS have not yet been fully defined, it is clear that the symptoms it addresses respond over a variable period. This phenomenon is evident in the use of DBS for movement disorders, with effects on tremor often noted within seconds, whereas effects on rigidity and bradykinesia may take minutes to hours to develop. Mechanistic differences are believed to underlie these various responses, with stimulation potentially having an immediate and direct modulatory effect on local circuitry, compared to its more latent effect on neural plasticity and neuronal reorganization over time..$^{12}$ It has been suggested that the response to DBS for pain may require a longer period of days to months than the response to DBS for other indications, ${ }^{1}$ which our findings support.

We found that patients were sensitive to small changes in programing parameters, particularly in frequency. As previously described, patients often respond to a narrow frequency range of stimulation (e.g., 30-50 Hz), ${ }^{11}$ and stimulation at higher frequencies can be paradoxically hyperalgesic. ${ }^{4}$ Ranges reported in the medical literature vary widely from 20 to $135 \mathrm{~Hz} .^{3}$ This variable range, combined with the lack of immediate feedback, poses an algorithmic programing challenge that can presently be overcome only with an informed trial-and-error approach over time with close attention paid to the parametric details of each program that is trialed. Given these requirements, it is not surprising that the trial length in our cohort ranged from 9 to 63 days. This trial duration is considerably longer than previously reported trials spanning 5-7 days, ${ }^{4,22}$ which calls into question whether previous trials and other study "failures" may have been ended prematurely.

The historical literature surrounding DBS for the treatment of chronic pain syndromes has been marked by inconsistency. Previous attempts by the device manufacturer in the 1990s to formally evaluate the safety and efficacy of DBS for pain had unacceptably high attrition rates, which were interpreted as indicating a failure of the therapy. Because the results were never formally published, the study methods and programming parameters are unclear. However, our results lead us to speculate that given the early attrition, the presumption of a lack of efficacy in these early exiting patients may be inappropriate.

DBS for the treatment of chronic neuropathic pain is presently a treatment of last resort in patients who have exhausted almost all other options. The severity of their pain and their ensuing disability make it somewhat arbitrary to define a threshold for efficacy as a measure of the success of the procedure. Ultimately, this decision should be based on the individual circumstances of the patient. For carefully selected patients, practitioners should weigh the risks of performing DBS against the risks of no intervention, which may include continued loss of quality of life, loss of employment, reliance on medications, and even loss of life. Our current techniques are limited to a combination of indirect and roughly direct targeting strategies. However, with continuous refinement of targets using new anatomical models and imaging modalities, as well as improvements in the functionality of implanted hardware, practitioners can continue to optimize this therapeutic modality and collect data to inspire new and better-designed studies to obtain Level I evidence of efficacy.

\section{Conclusions}

DBS of the VPM and PAG is a potential therapeutic option for patients suffering from severe, intractable facial pain refractory to other interventions. Improved efficacy may be observed over time with close follow-up and active programming adjustments.

\section{Acknowledgments}

We thank the staff of Neuroscience Publications at Barrow Neurological Institute for assistance with manuscript preparation.

\section{References}

1. Ashkan K, Rogers P, Bergman H, Ughratdar I: Insights into the mechanisms of deep brain stimulation. Nat Rev Neurol 13:548-554, 2017

2. Benabid AL, Pollak P, Gervason C, Hoffmann D, Gao DM, Hommel M, et al: Long-term suppression of tremor by chronic stimulation of the ventral intermediate thalamic nucleus. Lancet 337:403-406, 1991

3. Boccard SG, Pereira EA, Aziz TZ: Deep brain stimulation for chronic pain. J Clin Neurosci 22:1537-1543, 2015

4. Boccard SG, Pereira EA, Moir L, Aziz TZ, Green AL: Longterm outcomes of deep brain stimulation for neuropathic pain. Neurosurgery 72:221-231, 2013

5. Boccard SGJ, Prangnell SJ, Pycroft L, Cheeran B, Moir L, Pereira EAC, et al: Long-term results of deep brain stimulation of the anterior cingulate cortex for neuropathic pain. World Neurosurg 106:625-637, 2017

6. Cleary DR, Ozpinar A, Raslan AM, Ko AL: Deep brain stimulation for psychiatric disorders: where we are now. Neurosurg Focus 38(6):E2, 2015

7. Coffey RJ: Deep brain stimulation for chronic pain: results of two multicenter trials and a structured review. Pain Med 2:183-192, 2001

8. Deuschl G, Schade-Brittinger C, Krack P, Volkmann J, Schäfer H, Bötzel K, et al: A randomized trial of deep-brain stimulation for Parkinson's disease. N Engl J Med 355:896908, 2006 
9. Fisher R, Salanova V, Witt T, Worth R, Henry T, Gross R, et al: Electrical stimulation of the anterior nucleus of thalamus for treatment of refractory epilepsy. Epilepsia 51:899-908, 2010

10. Gildenberg PL: Neurosurgical statement on neuroaugmentive devices. Appl Neurophysiol 40:69-71, 1977

11. Green AL, Owen SL, Davies P, Moir L, Aziz TZ: Deep brain stimulation for neuropathic cephalalgia. Cephalalgia 26:561-567, 2006

12. Herrington TM, Cheng JJ, Eskandar EN: Mechanisms of deep brain stimulation. J Neurophysiol 115:19-38, 2016

13. Hosobuchi Y, Adams JE, Rutkin B: Chronic thalamic stimulation for the control of facial anesthesia dolorosa. Arch Neurol 29:158-161, 1973

14. Kupsch A, Benecke R, Müller J, Trottenberg T, Schneider $\mathrm{GH}$, Poewe W, et al: Pallidal deep-brain stimulation in primary generalized or segmental dystonia. N Engl J Med 355:1978-1990, 2006

15. Lempka SF, Malone DA Jr, Hu B, Baker KB, Wyant A, Ozinga JG IV, et al: Randomized clinical trial of deep brain stimulation for poststroke pain. Ann Neurol 81:653-663, 2017

16. Lipsman N, Woodside DB, Giacobbe P, Hamani C, Carter JC, Norwood SJ, et al: Subcallosal cingulate deep brain stimulation for treatment-refractory anorexia nervosa: a phase 1 pilot trial. Lancet 381:1361-1370, 2013

17. Mayberg HS, Lozano AM, Voon V, McNeely HE, Seminowicz D, Hamani C, et al: Deep brain stimulation for treatmentresistant depression. Neuron 45:651-660, 2005

18. Obeso JA, Olanow CW, Rodriguez-Oroz MC, Krack P, Kumar R, Lang AE: Deep-brain stimulation of the subthalamic nucleus or the pars interna of the globus pallidus in Parkinson's disease. N Engl J Med 345:956-963, 2001

19. Ondo W, Jankovic J, Schwartz K, Almaguer M, Simpson RK: Unilateral thalamic deep brain stimulation for refractory essential tremor and Parkinson's disease tremor. Neurology 51:1063-1069, 1998

20. Pereira EA, Boccard SG, Linhares P, Chamadoira C, Rosas MJ, Abreu P, et al: Thalamic deep brain stimulation for neuropathic pain after amputation or brachial plexus avulsion. Neurosurg Focus 35(3):E7, 2013

21. Pereira EA, Wang S, Owen SL, Aziz TZ, Green AL: Human periventricular grey somatosensory evoked potentials suggest rostrocaudally inverted somatotopy. Stereotact Funct Neurosurg 91:290-297, 2013
22. Rasche D, Rinaldi PC, Young RF, Tronnier VM: Deep brain stimulation for the treatment of various chronic pain syndromes. Neurosurg Focus 21(6):E8, 2006

23. Schuepbach WM, Rau J, Knudsen K, Volkmann J, Krack P, Timmermann L, et al: Neurostimulation for Parkinson's disease with early motor complications. N Engl J Med 368:610-622, 2013

24. Vandewalle V, van der Linden C, Groenewegen HJ, Caemaert $\mathrm{J}$ : Stereotactic treatment of Gilles de la Tourette syndrome by high frequency stimulation of thalamus. Lancet 353:724, 1999

25. Vidailhet M, Vercueil L, Houeto JL, Krystkowiak P, Benabid AL, Cornu P, et al: Bilateral deep-brain stimulation of the globus pallidus in primary generalized dystonia. N Engl J Med 352:459-467, 2005

26. Weaver FM, Follett K, Stern M, Hur K, Harris C, Marks WJ $\mathrm{Jr}$, et al: Bilateral deep brain stimulation vs best medical therapy for patients with advanced Parkinson disease: a randomized controlled trial. JAMA 301:63-73, 2009

27. Williams A, Gill S, Varma T, Jenkinson C, Quinn N, Mitchell R, et al: Deep brain stimulation plus best medical therapy versus best medical therapy alone for advanced Parkinson's disease (PD SURG trial): a randomised, open-label trial. Lancet Neurol 9:581-591, 2010

\section{Disclosures}

The authors report no conflict of interest concerning the materials or methods used in this study or the findings specified in this paper.

\section{Author Contributions}

Conception and design: all authors. Acquisition of data: BenHaim, Rosenberg. Analysis and interpretation of data: all authors. Drafting the article: all authors. Critically revising the article: all authors. Reviewed submitted version of manuscript: all authors. Statistical analysis: Ben-Haim. Administrative/technical/material support: Ben-Haim, Mirzadeh. Study supervision: Rosenberg.

\section{Correspondence}

Sharona Ben-Haim: University of California, San Diego, CA. neuropub@barrowneuro.org. 